\title{
Rare hereditary nonspherocytic hemolytic anemia caused by novel homozygous mutation, c.301C>A, (Q101K) in the $A K 1$ gene in an Indian family
}

\section{Rashmi Dongerdiye}

National Institute of Immunohematology

Abhilasha Sampagar

Belgaon

Rati Devendra

National Institute of Immunohematology

Prashant Warang

National Institute of Immunohematology

Prabhakar Kedar ( $\square$ kedarps2002@yahoo.com )

National Institute of Immunohaematology https://orcid.org/0000-0003-3509-2913

Research article

Keywords: Adenylate kinase deficiency, enzymopathies, prenatal diagnosis, Congenital haemolytic anaemia

Posted Date: February 23rd, 2021

DOl: https://doi.org/10.21203/rs.3.rs-219658/v1

License: (c) (1) This work is licensed under a Creative Commons Attribution 4.0 International License.

Read Full License

Version of Record: A version of this preprint was published at BMC Medical Genomics on July 28th, 2021. See the published version at https://doi.org/10.1186/s12920-021-01038-2. 


\section{Abstract}

\section{Background}

Adenylate kinase (AK) deficiency is an uncommon form of congenital non-spherocytic haemolytic anaemia. To date, only 13 families have been affected by this disorder exhibiting symptoms like chronic anaemia supported by recurrent blood transfusions, jaundice, hepatosplenomegaly, and mental and psychomotor retardation in exceptional cases. This study aimed to identify a pathogenic mutation in the undiagnosed case of haemolytic anemia and to offer a parental diagnosis in the subsequent pregnancy.

Method

Next-generation sequencing (NGS) was performed to identify pathogenic variants in the patient. Prenatal diagnosis during the second pregnancy was performed on genetic testing was performed on chronic villus sample (CVS) collected in 11 weeks of pregnancy from the mother and intravenous blood was drawn from both the parents.

Results

Novel causative mutation (p. Gln101Lys) in the AK gene was identified in a 5-year-old male child with severe transfusion-dependent hemolytic anemia. Bioinformatics tools predicted the deleterious effect of the novel variant on the structure of the protein. Prenatal diagnosis of the fetus was found to be heterozygous for the mutation. Both the parents were heterozygous for the variant c.301C > A, p. Gln101Lys.

Conclusion

We have presented a review of the literature and novel mutations in the AK1 gene (p. Gln101 Lys) associated with adenylate kinase deficiency. It is first a prenatal diagnosis AK deficiency report from India where heterogeneity is too high in the population and custom of intra-community marriages are prevalent.

\section{Background}

Adenylate kinase (AK) deficiency is an inherited blood disorder associated with rare hereditary nonspherocytic haemolytic anaemia [1]. Adenylate kinase (ATP-AMP phosphotransferase, EC 2.7.4.3) is a ubiquitous enzyme, catalyzes the reversible transfer of phosphate moiety among ATP, ADP, and AMP and enriches the homeostasis of the adenine nucleotide composition in the cell [2]. Common symptoms include haemolytic crisis supported by regular blood transfusion, jaundice, hepatosplenomegaly, and psychomotor retardation in exceptional cases [3]. AK1 is mainly expressed in tissue with a high turnover rate in blood, brain, and muscles. AK deficiency is caused due to a defect in the $A K 1$ gene which is located on the ninth chromosome (9q34.11). Panayiotou $C$ et. al. study suggests six isoforms of AK enzyme expressed in different mammalian tissues. $A K 1$ is mainly expressed in tissue with a high turnover 
rate in blood, brain, and muscles. In mammals, there are three isoenzymes of AK have been characterized. AK1 is present in the erythrocyte cytosol as well as in skeletal muscle and brain [4]. Adenylate kinase deficiency is rarely reported as a cause of congenital non-spherocytic haemolytic anaemia. AK deficient patient is usually transfusion-dependent; however, splenectomy has resolved AK deficiency. AK is an important enzyme in the red cell for nucleotide metabolism and responsible for correct interconversion of nucleotide phosphate which is available for physiological function. Recently the molecular organization of the $A K 1$ gene has been established. The gene is $12 \mathrm{~kb}$ long and it has seven exons. The mRNA is present in two sizes of 0.9 and $2.5 \mathrm{~kb}$, which differ at the 3'end. According to the available literature, 13 unrelated families with only 10 different $A K 1$ gene mutations have been reported, mainly seven missense, one frameshift, one nonsense, and one deletion mutation. There are three mutations (p. Arg97Trp and p. Arg107Stop, c.138delG) that are associated with psychomotor retardation whereas other mutations are associated with only moderate to severe transfusion dependant haemolytic anaemia (Table-1)[5-8].

We have developed next-generation sequencing (NGS) technology panel for congenital haemolytic anaemia to know the cause of unexplained transfusion dependant haemolytic anaemia. The panel mainly includes targeted genes that are associated with red cell haemolglobinopathies, enzymopathies, red cell membrane disorders, congenital dyserythropoietic anaemias, and bone marrow failure syndromes. These NGS gene panels covered a sequence of coding regions, splice site junctions, and deep intronic regions, and regulatory regions, which has the advantages to overcome all the problems in the diagnosis of unexplained haemolytic anaemia cases, especially in identifying de novo mutations [9]. This NGS panel gives fast and accurate results for identifying the genetic diagnosis in patients with unexplained congenital haemolytic anaemia. The pathogenic nature of the identified variant by NGS needs to be further confirmed by the published literature and a set of bioinformatics tools like 1000 Genome database, ClinVar, GWAS, and OMIM. The non-synonymous variant's effect also requires to study by multiple algorithms such as Mutation Taster2, PolyPhen-2, SIFT, and Mutation Assessor. However, integrated patient family history, clinical and molecular testing, and pedigree analysis are beneficial for these patients and families. We have reported a rare case of unexplained haemolytic anaemia due to a novel mutation c.301C>A, (p.GIn101Lys) in the $A K 1$ gene in a non-consanguineous Indian family, that subsequently helped the family in prenatal diagnosis, and also we have updated the mutations spectrum of adenylate kinase including a novel mutation found in this study.

\section{Methods}

\section{Patients}

The proband is a 5 years old male child, resident of Kolhapur Maharashtra (India), born of a nonconsanguineous Indian family. He had severe anaemia $(\mathrm{Hb}-5.7 \mathrm{~g} / \mathrm{dl})$ at the age of 3 months and was given packed red blood cell support. Since then he is on regular blood transfusions requiring the interval of every 2-3 months. The patient was extensively studied at the biochemical level to find out the cause of haemolysis. HPLC of proband and parents performed during the initial investigation indicates the absence of haemoglobinopathies. The peripheral blood smear shows a dimorphic picture. Bone marrow 
examination shows erythroid hyperplasia with megaloblasts. He has hepatosplenomegaly with liver$4 \mathrm{cms}$ in size and spleen up to umbilicus. He has no history of fever and skin rashes. After informed consent from the parents, $10 \mathrm{ml}$ of blood was collected in an EDTA bulb. Test for the common cause of haemolytic anaemia which mainly includes haemoglobinopathies (Thalassemia and sickle cell anaemia), red cell enzymopathies (G6PD, PK, and GPI), and membranopathies were performed and found to be within the normal limit. After all these investigations, the patient had an unexplained cause of haemolytic anaemia.

\section{Molecular studies}

Eventually, targeted NGS was performed to rule out the rare cause of haemolysis. DNA extracted from blood was used to perform targeted gene capture using a custom capture kit. The libraries were sequenced to mean $>80-100 \mathrm{X}$ coverage on the Illumina sequencing platform. The variant identified was further confirmed with both the parent's DNA sample by DNA Sanger sequencing, also further confirmed by measuring enzyme AK enzyme activity in a freshly collected blood sample. Further, the family decided to undergo prenatal diagnosis at the time of the second pregnancy based on the severe presentation in the proband.

\section{Prenatal diagnosis and Detection of the familial AK deficiency causative mutation}

Chronic Villus Sample (CVS) was collected under the supervision of a gynecologist during the 11 weeks of pregnancy from the mother. Genomic DNA was isolated from the CVS sample by Qiagen FlexiGene DNA Kit also intravenous blood was drawn and genomic DNA was isolated from both the parents. Primers used for DNA amplification and identification of variants are based on the standard protocol mentioned previously [5]. DNA Sanger sequencing was run on the Applied Biosystems 3730XL DNA analyzer to detect the disease-causing mutations. Kleihauer-Betke (KB) staining test was performed to check for the intervention of the mother's sample in the fetus sample. The parents and family were counseled accordingly.

\section{Bioinformatics analysis}

The crystallographic model of the recombinant human Adenylate kinase (EC 2.7.4.3) was downloaded from the Protein Data Bank (www.rcsb.org/pdb/; PDB-ID: IZ83) [10] and the impact of an amino acid substitution on the structure and function of the protein was analyzed using PyMol software (DeLano Scientific, San Carlos, CA, USA) (http://www.pymol.org/ ) and Swiss Protein databank viewer (https://spdbv.vital-it.ch/) which help us to visualize the position and molecular surroundings within the AK protein [11].

\section{Results}


His complete blood count, at time of study was WBC $9.1 \times 10^{3} / \mathrm{ul}, \mathrm{RBC}-2.14 \times 10^{6} / \mathrm{ul}, \mathrm{HB}-6.2 \mathrm{~g} / \mathrm{dl}$, HCT18.5\%, MCV-86.4fl, MCH-28.5pg, MCHC-33 g/dl, PLT-111x10\%3/ul, RDW-23.9\%. He showed elevated indirect bilirubin, $\mathrm{LDH}$, and reticulocyte count (8.8\%), total bilirubin- $2.3 \mathrm{mg} / \mathrm{dl}$, indirect bilirubin- $1.5 \mathrm{mg} / \mathrm{dl}, \mathrm{LDH}-$ $3400 \mathrm{IU} / \mathrm{L}$. All investigations were suggestive of haemolytic crisis. RBC membranopathies were found to be normal reveals by the EMA test showed - 980 MCF (Mean channel fluorescence). This implies that he would be a case of RBC enzymopathy. Although the common red metabolic enzymes study were found to be normal. G6PD-5.6 IU/gHb, PK-9.1 IU/gHb, GPI-59.6 IU/gHb. The haematological biochemical and molecular data of the proband and parents are summarized in Table-2.

The proband sample was subjected to targeted NGS. The human reference genome (GRCh37/hg19) and obtained sequence are aligning by the BWA software and Picard and GATK version 3.6 used to analyze to identify relevant variants associated with the clinical presentations. The clinically relevant variant was annotated with the published literature and aggregates the information using databases likes ClinVar, OMIM, GWAS, HGMD, and SwissVar. NGS result revealed a novel homozygous substitution in exon 4 of AK1 gene - c.301C > A, p. GIn101Lys. DNA Sanger sequencing confirmed the homozygosity status of the proband and heterozygous in the parents (Figure-1). This was later confirmed with both the parent's DNA sample and validated by DNA Sanger sequencing, also further confirmed by measuring enzyme AK enzyme activity in a freshly collected blood sample. AK activity was found to be $(38.0 \mathrm{lU} / \mathbf{g ~ H b})$ deficient, mother showed $192.0 \mathrm{IU} / \mathrm{gHb}$ and the father showed $208.0 \mathrm{IU} / \mathrm{gHb}$ activity, whereas 50 normal healthy controls showed in the range of $297-360 \mathrm{IU} / \mathrm{gHb}$. Further, the family decided to undergo prenatal diagnosis at the time of the second pregnancy based on the results of the proband. Subsequent biochemical analysis of the proband and the parents confirmed the molecular study result.

The fetus, as well as parent genomic DNA, was subjected to DNA Sanger sequencing based on the identified variant in the $A K 1$ gene in Exon-4 c.301C > A, p. GIn101Lys in the index case by NGS. The fetus and both the parents were heterozygous, whereas only the proband was homozygous for the aforementioned variant. After reconfirmation from KB staining that there is no indication of the remnant of the mother's sample in the fetus, the results were discussed with the couples. The couples were thoroughly counselled and given necessary genetic advice. The pregnancy was continued and the normal healthy child was born post gestation period of 9 months.

This novel variant changes the structure of AK protein as it has a deleterious effect which was confirmed by bioinformatics tools. According to the available list of mutations in HGMD, this substitution has not been mentioned in the database. All the prediction tools -Polyphen-2, SIFT, PROVEAN, Mutation taster, Mutation Assessor, PMUT, MutPred2, have been explored to evaluate the effect of the variants on the structure of the protein. Table-3 summarizes the multiple bioinformatics software's prediction results of $p$. GIn101Lys. The entire prediction tool suggested the damaging effect of the amino acid change from glutamine to lysine. AK1 protein (PDB ID-1Z83) consists of three chains A, B, C, spanning to the length of 194 residues. Each chain consists of one large central "CORE" domain and two small peripheral domains, NMP binding domain, and the LID domain. Upon ATP binding, the LID domain closes over the phosphoryl transfer site. The amino acid residue position Q101 is an important AMP binding site, along with 
$39,44,138,149$ residues. Any changes at these AMP binding sites possibly hamper the catalytic cycle of the enzyme. Figure 2A showed complete ribbon representation of protein (PDB ID-1Z83) with chain A, B, C which highlights the three chains of the AK1 enzyme, along with insight at the Q101 position's helical structure and amino acid change from wild type (glutamine) to mutant type (lysine), (B) Secondary structure of the protein (PDB ID-1Z83) showing amino acid residue at position 101(Q101), (C) Wild type amino acid residue Glutamine 101 (Q101), (D) Mutant type amino acid residue Lysine101 (K101) and (E) showed the residue (Q) at positions 101 of AK-1 is highly conserved across species. Bioinformatics prediction tools have confirmed the damaging effect of the variant on the structure of the enzyme and demonstrated its conversation throughout the species [10-11].

\section{Discussion}

In this paper, we have described the family with a very rare red cell enzymopathies of Adenylate kinase deficiency is an autosomal recessive disease. We have presented our novel method for diagnosis of unexplained hemolytic anemia for couple would be at risk of disease. We have presented a review of the literature and novel mutations in the AK1 gene (p. Gln101Lys) associated with adenylate kinase deficiency. It is the first of its kind report from India where heterogeneity is too high in the population and custom of intra-community marriages are prevalent. Prenatal diagnosis is a very useful technique to guide healthcare professionals and affected families regarding the decision for pregnancy management, delivery options, and postnatal treatment. However, accurate genetic advice accomplished with a prenatal diagnosis by use of NGS can help in managing the genetic disorder [12]. Prenatal diagnosis results of the fetus sample showed a heterozygous missense mutation in the $A K 1$ gene in Exon 4- c.301C > A (p.GIn101Lys). During the pregnancy period, it was monitoring closely, and prenatal ultrasonography results suggested a normal intrauterine growth and were born healthy and asymptomatic. NGS has helped in identifying rare metabolic enzyme defects like AK deficiency; however, its utilization for routine diagnosis needs to be explored. Besides, genetic variability is still extremely high in our community, closeknit marriages only worsen the situations [13-14]. In this family study, the proband was the outcome of a non-consanguineous marriage; even then both the parent and fetus were heterozygous for the variant. This increases the chance of homozygosity in the community if intra-community marriages prevailed. However, accurate genetic advice accomplished with prenatal diagnosis and awareness among people can keep a check on the growth of genetic disorders [15]. This is the rare report of AK deficiency from India where heterogeneity is too high in the population and custom of intra-community marriages are prevalent. However, accurate genetic advice accomplished with a prenatal diagnosis can help in managing the genetic disorder.

Molecular approaches for the diagnosis of rare congenital anaemia defects include Sanger sequencing and NGS. Now as days, conventional Sanger sequencing, is generally used in a routine diagnostic tool for many genetic disorders but has its limitation in identifying de novo mutations whereas the variant is very rare and that is located outside of the captured regions, NGS targeted panel is very useful for identifying rare blood disorder. NGS has a higher diagnostic value as it has high accuracy and rapidly adapted in the genetic analysis [9]. Therefore, we used a targeted NGS panel for the analysis of 100 genes responsible 
for rare congenital anaemias, which successfully helped in identifying novel mutations in the $A K 1$ gene in Indian patients.

\section{Conclusion}

In conclusion, the targeted NGS panel help to identify a novel causative mutation in the $A K 1$ gene in a 5year-old male child with severe transfusion-dependent haemolytic anaemia. Identification of the pathogenic mutation helps us to offer a prenatal diagnosis in this family. This study also re-emphasizes the importance of NGS for the diagnosis and treatment of unexplained haemolytic anaemia in affected individuals.

\section{Abbreviations}

ADP - Adenosine-Di-Phosphate

AK - Adenylate Kinase

AMP - Adenosine Mono Phosphate

ATP - Adenosine Tri Phosphate

BWA - Burrows Wheeler Alignment

CVS - Chronic Villus Sample

DNA - Deoxyribonucleic acid

EDTA - Ethylene diamine tetraacetic acid

EMA - Eosin 5 Maleimide

G6PD - Glucose-6-phosphate-dehydrogenase

GATK - Genome analysis tool kit

GPI -Glucose phosphate isomerase

GWAS -Genome wide association study

HB - Haemoglobin

HCT - Hematocrit

HGMD -Human genome mutation database

HPLC - High performance liquid chromatography 
KB - Kleihauer-betke

LDH - Lactate dehydrogenase

MCF - Mean channel fluorescence

$\mathrm{MCH}$ - Mean corpuscular hemoglobin

MCHC - Mean corpuscular hemoglobin concentration

MCV - Mean corpuscular volume

mRNA -Messenger ribonucleic acid

NGS - Next-generation sequencing

NMP - Nucleoside monophosphate

OMIM - Mnline mendelian inheritance in man

PDB - Protein data bank

PK -Pyruvate kinase

PLT -Platelet

PROVEAN - Protein variation effect analyzer

RBC -Red blood cell

RDW - Red cell distribution width

SIFT -Sorting intolerant from tolerant

WBC - White blood cell

\section{Declarations}

\section{Ethics approval and consent to participate}

This study was approved by the Ethics Committee of the Institutional Ethical Committee of ICMRNational Institute of Immunohaematology, Mumbai. All procedures performed in studies involving human participants were per the ethical standards of the institutional review board of the Institute and with the 1964 Helsinki declaration and its later amendments or comparable ethical standards. Written informed consent was obtained from all individual participants included in this study. 
Written consent was obtained from all the participants or their guardians for the publication of this study.

\section{Availability of data and materials}

The data used to support the findings of this study are included within the article.

\section{Competing Interest:}

The authors declare that they have no conflict of interest.

\section{Funding:}

The fees of NGS sequencing and data analysis were funded by the Department of Biotechnology New Delhi (DBT Project No. BT/PR20782/MED/12/737/2016) and Indian Council of Medical Research New Delhi. The funder had no role in the study design, data collection, analysis, decision to publish, or manuscript preparation.

\section{Author contributions}

PK and RD designed the experiment. RD, AS, RT, and PW collected samples and conducted the study. PK and RD analyzed the data. PK, and RD wrote the paper. All authors read and approved the final manuscript

\section{Acknowledgments}

We would like to thank patients and family members for their cooperation and participation in this study. This study was performed with the support of the Indian Council of Medical Research New Delhi, and the Department of Biotechnology (DBT) New Delhi for financial support. The authors' sincere thanks are due to Medgenome Laboratories Ltd. for NGS of the AK1 gene for the index case.

\section{References}

1. Niizuma $\mathrm{H}$, et al. Splenectomy resolves hemolytic anemia caused by adenylate kinase deficiency. Int. 2017; 59:228-230.

2. Bianchi $P$, et al. A case of complete adenylate kinase deficiency due to a nonsense mutation in the AK-1 gene (Arg 107> Stop, CGA>TGA) associated with chronic hemolytic anemia. J. Haematol.1999; 105: 75-79.

3. Fermo E, et al. A new variant of adenylate kinase (delG138) associated with severe hemolytic anemia. Blood Cells Mol Dis. 2004; 33: 146-149.

4. Panayiotou C, Solaroli N, Karlsson A. The many isoforms of human adenylate kinases. J. Biochem. Cell Biol. 2014; 49:75-83.

5. Dongerdiye $R$, et al. Red cell adenylate kinase deficiency in India: identification of two novel missense mutations (c.71A>G and c.413G>A). Clin. Pathol. 2019; 72:393-398. 
6. Ren $\mathrm{H}$, et al. The crystal structure of human adenylate kinase 6 : an adenylate kinase localized to the cell nucleus. Natl. Acad. Sci. U S A. 2005; 102:303-308.

7. Abrusci P, et al. Erythrocyte adenylate kinase deficiency: characterization of recombinant mutant forms and relationship with nonspherocytic hemolytic anemia. Hematol.2007; 35 :1182-1189.

8. Diederichs K, Schulz GE. The refined structure of the complex between adenylate kinase from beef heart mitochondrial matrix and its substrate AMP at 1.85 A resolution. Mol. Biol. 1991; $217: 541-$ 549 .

9. Corrons J-LV, Garcia E, Tusell JJ, et al. Red cell adenylate kinase deficiency: a molecular study of 3 new mutations (118G >A, 190G $>A$, and GAC deletion) associated with hereditary nonspherocytic hemolytic anemia. Blood 200; 102: 353-356.

10. Matsuura S, Igarashi M, Tanizawa Y, et al. Human adenylate kinase deficiency associated with hemolytic anemia. A single base substitution affecting solubility and catalytic activity of the cytosolic adenylate kinase. J Biol. Chem. 1989; 264:10148-10155.

11. Qualtieri A, Pedace V, Bisconte MG, et al. Severe erythrocyte adenylate kinase deficiency due to homozygous $A \rightarrow G$ substitution at codon 164 of human AK1 gene associated with chronic haemolytic anaemia. J Hematol. 1997; 99:770-776.

12. Chandler N, Best S, Hayward J, Faravelli F, Mansour S, Kivuva E, Tapon D. Rapid prenatal diagnosis using targeted exome sequencing: a cohort study to assess feasibility and potential impact on prenatal counseling and pregnancy management. Gen Med Vol. 2018;20:1430-8.

13. Verma IC, Bijarnia S. The burden of genetic disorders in India and a framework for community control. Community Genet. 2002;5:192-196.

14. Bijarnia-Mahay S, Arora V, Saxena R, Verma IC. The changing scenario in prenatal diagnosis of genetic disorders: genetics to genomics. Curr Med Res Pract. 2018;1:8203-8208.

15. Madan N, Sharma S, Sood SK, Colah R, Bhatia LH. Frequency of $\beta$-thalassemia trait and other hemoglobinopathies in northern and western India. Indian J Hum Genet. 2010; 16:16-25

\section{Tables}

Table-1 : Mutations update in $A K 1$ gene 


\begin{tabular}{|c|c|c|c|c|c|}
\hline $\begin{array}{l}\text { Sr. } \\
\text { No }\end{array}$ & $\begin{array}{l}\text { Type of } \\
\text { Mutation }\end{array}$ & $\begin{array}{l}\text { Nucleotide } \\
\text { change }\end{array}$ & $\begin{array}{l}\text { Amino acid } \\
\text { change }\end{array}$ & Origin & References \\
\hline 1. & Missense & c. $71 A>G$ & p.GIn24Arg & Indian & $\begin{array}{l}\text { R. Dongerdiye et al } \\
\text { (2019) [4] }\end{array}$ \\
\hline 2. & Missense & c. $118 \mathrm{G}>\mathrm{A}$ & p.Gly40Arg & Spanish & $\begin{array}{l}\text { V. Corrons et } \\
\text { al (2003)[11] }\end{array}$ \\
\hline 3. & Frameshift & c.138delG & Framshift & Italian & $\begin{array}{l}\text { Fermo et al } \\
(2004)[3]\end{array}$ \\
\hline 4. & Missense & c. $190 \mathrm{G}>\mathrm{A}$ & p.Gly64Arg & Spanish & $\begin{array}{l}\text { V. Corrons et } \\
\text { al (2003) [11] }\end{array}$ \\
\hline 5. & Missense & c. $289 \mathrm{C}>\mathrm{T}$ & p.Arg97Trp* & Japanese & $\begin{array}{l}\text { Niizuma et al } \\
\text { (2017) [1] }\end{array}$ \\
\hline 6. & Missense & c. $301 C>A$ & p. Gln101Lys & Indian & This Paper \\
\hline 7. & Nonsense & c. $319 \mathrm{C}>\mathrm{T}$ & p.Arg107Stop* & Italian & $\begin{array}{l}\text { P. Bianchi et al (1999) } \\
\text { [2] }\end{array}$ \\
\hline 8. & Missense & c. $382 C>T$ & p.Arg128Trp & Japan & $\begin{array}{l}\text { Matsuura et al(1989) } \\
\text { [9] }\end{array}$ \\
\hline 9. & Missense & c. $413 G>A$ & p.Arg138His & Indian & $\begin{array}{l}\text { R. Dongerdiye et al } \\
(2019)[4]\end{array}$ \\
\hline 10. & Deletion & c.418_420delGAC & DeletionD140 & English & $\begin{array}{l}\text { V. Corrons et } \\
\text { al (2003) [11] }\end{array}$ \\
\hline 11. & Missense & c. $491 A>G$ & p.Tyr164Cys & Italian & $\begin{array}{l}\text { Qualtieri et al(1997) } \\
\text { [10] }\end{array}$ \\
\hline
\end{tabular}

*Mutations associated with psychomotor retardation.

Table-2 : Haematological biochemical and molecular data of the proband and parents 


\begin{tabular}{|c|c|c|c|c|}
\hline Parameters & Proband & Father & Mother & $\begin{array}{l}\text { Normal } \\
\text { Range }\end{array}$ \\
\hline Age/Sex & $5 y r s / M$ & $36 y r s / M$ & $30 \mathrm{yrs} / \mathrm{F}$ & - \\
\hline Place of origin & \multicolumn{4}{|c|}{ Kolhapur Maharashtra (India) } \\
\hline \multicolumn{5}{|l|}{ Haematological } \\
\hline White Blood cell $\left(\times 10^{3} / \mu \mathrm{l}\right)$ & 9.1 & 8.0 & 9.1 & $4-10$ \\
\hline Red blood cell $\left(\times 10^{6} / \mu \mathrm{l}\right)$ & 2.14 & 5.03 & 4.53 & $\begin{array}{l}\text { M-4.5- } \\
5.5 ; \text { F- } \\
3.8-4.8\end{array}$ \\
\hline Haemoglobin(g/dl) & 6.2 & 14.1 & 11.6 & $\begin{array}{l}\text { M-13- } \\
17 ; \mathrm{F}- \\
12-16\end{array}$ \\
\hline Haematocrit (\%) & 18.5 & 45.7 & 35.7 & $\begin{array}{l}\text { M-45- } \\
50 ; \mathrm{F}- \\
37-45\end{array}$ \\
\hline Mean Corpuscular Volume(fl) & 86.4 & 91.0 & 78.8 & $80-100$ \\
\hline Mean Corpuscular Haemoglobin (Pg) & 28.5 & 28.0 & 25.6 & $27-32$ \\
\hline $\begin{array}{l}\text { Mean Corpuscular Haemoglobin } \\
\text { Concentration }(\mathrm{g} / \mathrm{dl})\end{array}$ & 33 & 30.8 & 32.5 & $32-36$ \\
\hline Platelet $\left(\mathrm{x} 10^{3} / \mu \mathrm{l}\right)$ & 111 & 487 & 291 & $\begin{array}{l}150- \\
400\end{array}$ \\
\hline Red cell distribution width (\%) & 23.9 & 13.5 & 15.8 & $\begin{array}{l}11.6- \\
14\end{array}$ \\
\hline Retic count (\%) & 8.8 & ND & ND & $<2.0$ \\
\hline \multicolumn{5}{|l|}{ Biochemical and enzyme activity } \\
\hline Lactate Dehydrogenase (U/L) & 3400 & ND & ND & $\begin{array}{l}140- \\
280\end{array}$ \\
\hline Total Bilirubin (mg/dl) & 2.3 & ND & ND & $0.1-1.2$ \\
\hline Direct Bilirubin (mg/dl) & 0.8 & ND & ND & $<0.3$ \\
\hline Hemoglobin F (\%) & 1.3 & 0.0 & 0.0 & $<2.0$ \\
\hline Hemoglobin $A_{2}(\%)$ & 3.0 & 3.2 & 3.0 & $1.5-3.5$ \\
\hline $\begin{array}{l}\text { Glucose-6 Phosphate dehydrogenase } \\
(\mathrm{IU} / \mathrm{gHb})\end{array}$ & 5.6 & 6.3 & 5.0 & $\begin{array}{l}4.0- \\
13.0\end{array}$ \\
\hline Pyruvate kinase (IU/gHb) & 9.1 & 10.3 & 8.2 & $\begin{array}{l}8.0- \\
14.0\end{array}$ \\
\hline Adenylate kinase (IU/gHb) & $\begin{array}{l}38 \\
\text { Page } 12\end{array}$ & 192 & 208 & 297- \\
\hline
\end{tabular}




$\begin{array}{lllll}\text { Glucose Phosphate Isomerase }(\mathrm{IU} / \mathrm{gHb}) & 59.6 & 62.5 & 63 & 45-75 \\ \text { EMA (MCF) } & 980.97 & 956.70 & 946.85 & 900- \\ & & & & 1300\end{array}$

\section{Molecular}

Nucleotide Change

Amino acid change

Zygosity c. $301 \mathrm{C}>\mathrm{A}$

p. Gln101Lys

Homozygous Heterozygous Heterozygous

Table-3 : The multiple bioinformatics software's prediction results of $p$. Gln101Lys

\begin{tabular}{|lll|}
\hline Tool & Score & Prediction results \\
\hline Polyphen-2 & 1.00 & Damaging \\
\hline PROVEAN & -3.969 & Deleterious \\
\hline Mutation Taster & - & Disease-causing \\
\hline Mutation Assessor & 4.965 & HIGH \\
\hline MUTPRED2 & 0.882 & Pathogenic \\
\hline SIFT & 0.001 & Damaging \\
\hline PMUT & $94 \%$ & Disease \\
\hline
\end{tabular}

The results of the prediction are as shown in the table, and the meaning of scores is as follows:

1. PolyPhen-2: Scores are evaluated as 0.000 (most probably benign) to 1.000 (most probably damaging).

2. PROVEAN: Variants with a score above -2.5 are considered 'neutral'; score equal to or below -2.5 are considered 'deleterious.

3. Mutation Taster: A probability close to 1 indicates high security of prediction.

4. Mutation Assessor: It employs information based on the analysis of evolutionary conservation patterns in protein family multiple sequence alignments

5. MUTPRED2: This web application is developed to classify amino acid substitutions as pathogenic or benign in human

6. SIFT: Scores range from 0 to 1 , the score $\leq 0.05$ (damaging), $>0.05$ (tolerated).

7. PMUT: A web-based tooffor the annotation of pathological mutations on proteins

\section{Figures}




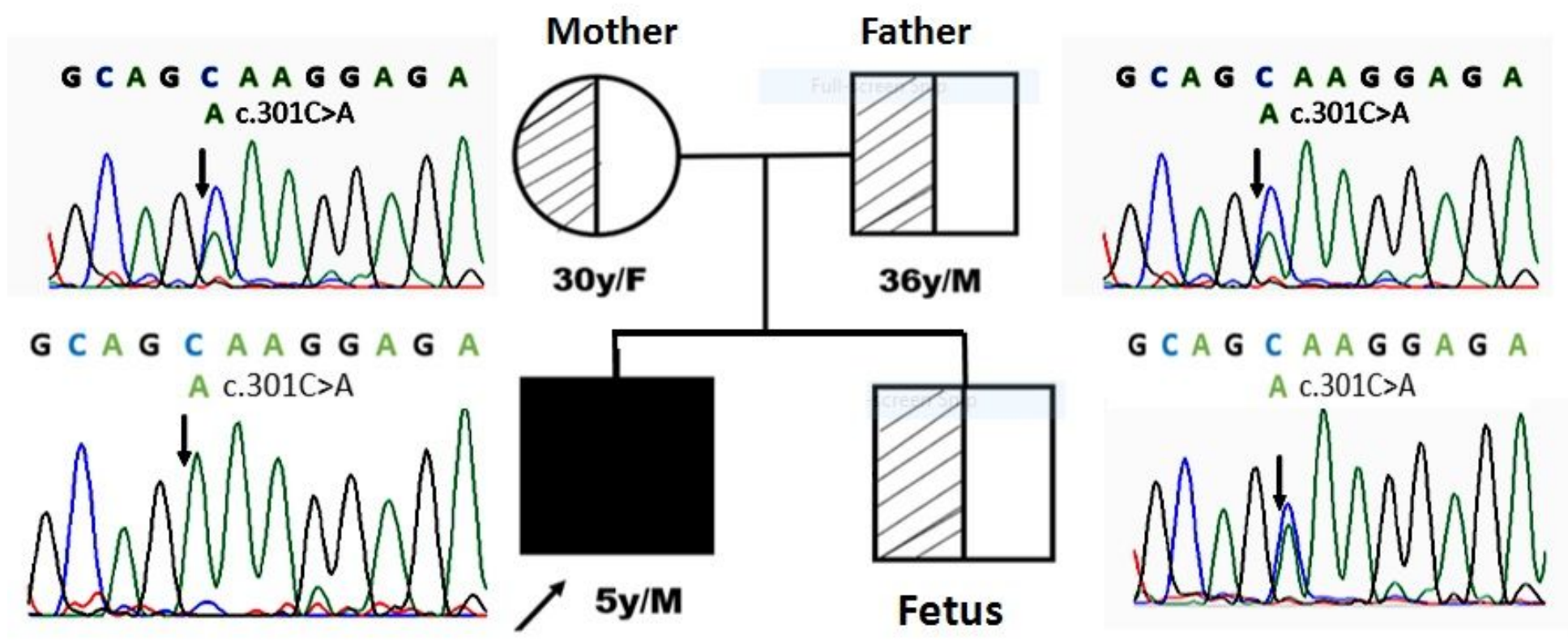

Figure 1

(A) Pedigree of the family, (B) Electropherogram of the AK1 gene shows a variant in Exon 4- c.301C>A p.Q101K in the parent, proband and fetus sample.
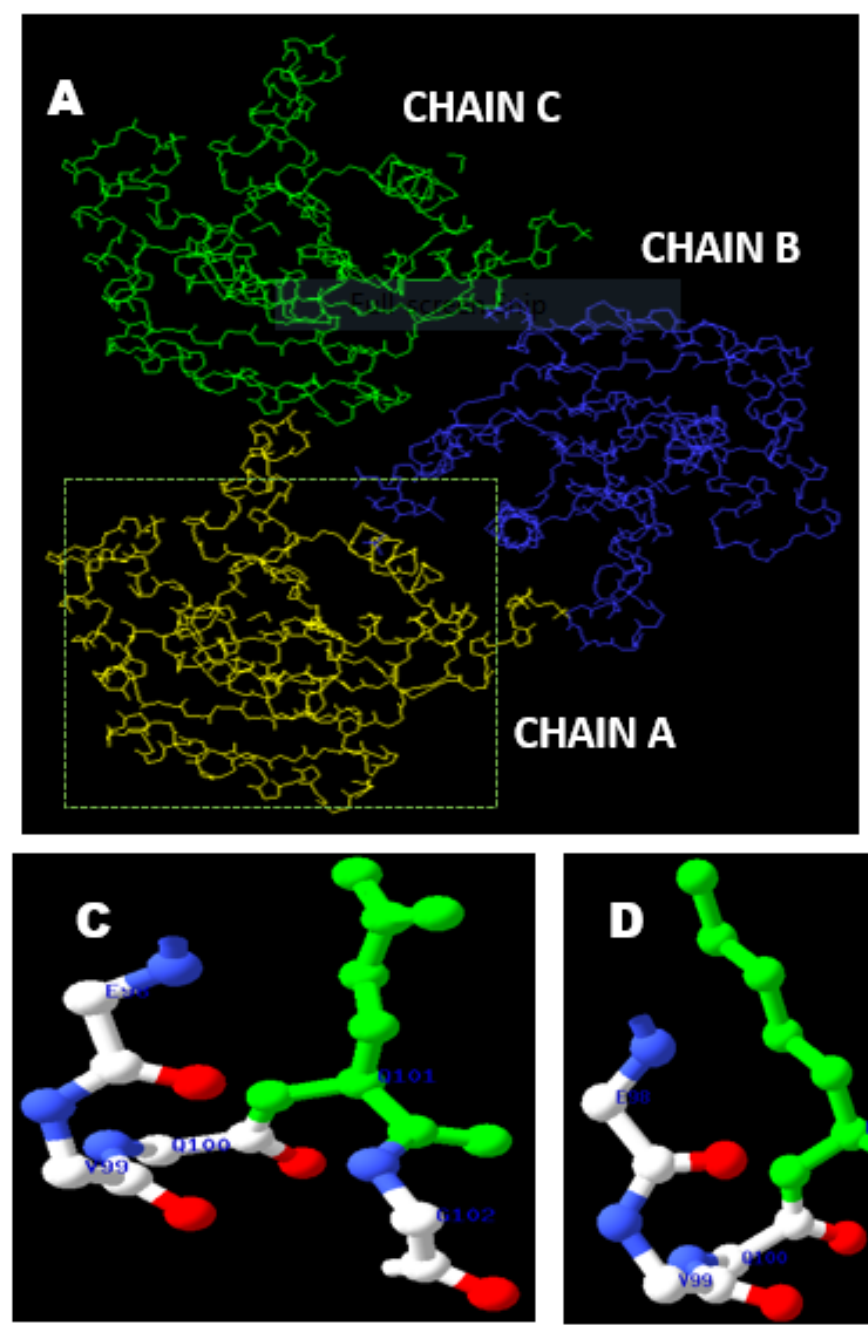

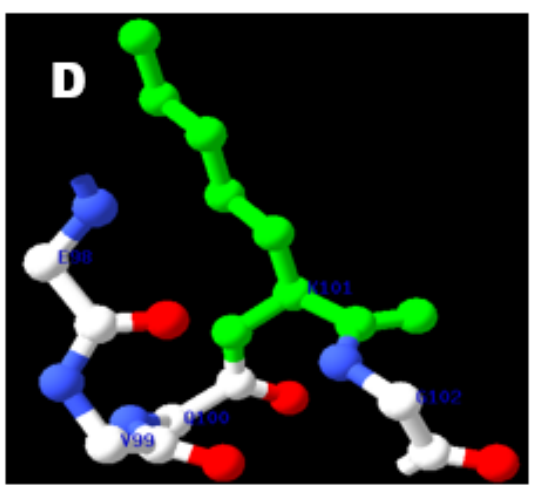

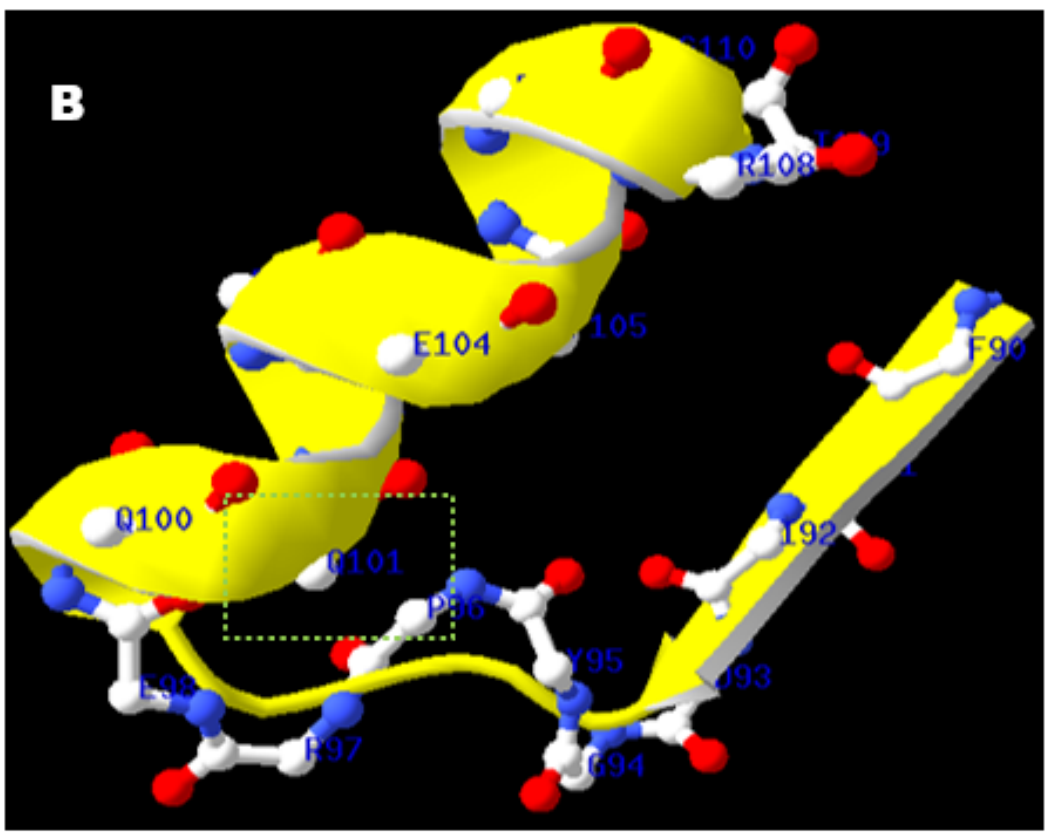

\section{E Q101K}

JuNGLEFOWL KADTSKGFLLIDGYPREV WGGEEFEKKIAPPTLLLWW 120 HUMAN KVITSKGFLIDGYPREVIGGEEFERRIGQPTLLLWDO 119 WHALE KVDTSKGFLIDGYPREVIMGEEFERRIGHPTLLLWD 119 NOUSE KVDSSNGFLIDGYPREVIMGEEFEQKIGOPTLLLWD 119 RAT KVDSSNGFLIDGYPREV MGgEEERKIAQPTLLLLWD 119

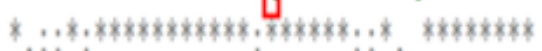


Figure 2

(A) Complete ribbon representation of protein (PDB ID-1Z83) with chain A, B, C. (B) Secondary structure of the protein (PDB ID-1Z83) showing amino acid residue at Position 101(Q101) (C) Wild type amino acid residue Glutamine 101 (Q101) (D) Mutant type amino acid residue Lysine101 (K101) (E) The residue (Q) at positions 101 of AK-1 is highly conserved across species 